\title{
EFFECT OF PHARMACOLOGICAL DOSES OF GARLIC AND OMEGA 3 ON GASTRIC LESIONS INDUCED BY ETHANOL IN MICE
}

\author{
AUSAMA AYOB JACCOB \\ Department of Pharmacology and Toxicology, College of Pharmacy, Basrah University, Basrah, Iraq. \\ Email: ausama1979@yahoo.com, ausamaphdjaccob@yahoo.com
}

Received: 14 May 2016, Revised and Accepted: 24 May 2016

\section{ABSTRACT}

Objective: This work was designed to investigate and compare the possible protective effect of pharmacological doses of garlic and omega 3 against gastric lesions induced by ethanol in mice.

Methods: A total of 30 mice involved in the study were divided into five groups with 6 mice for each. Groups 1 (ulcer control) and 2 (normal control), Groups 3 (positive ulcer control treated with ranitidine $50 \mathrm{mg} / \mathrm{kg}$ ), Groups 4 and 5 treated with garlic oil and omega 3 oil at doses $200 \mathrm{and} 150 \mathrm{mg} / \mathrm{kg}$, respectively. All groups treated orally by gastric gavage once daily for 14 days before starting gastric ulcer (GU) induction process by absolute ethanol administration.

Results: A treatment with garlic and omega 3 ameliorated the severity of gastric ulceration evidenced by reduced ulcer index area, increase \% gastroprotection, increase mucus content, reduced erosions, and necrosis.

Conclusion: Oral administration of pharmacological doses of garlic oil and omega 3 oil shows significant gastroprotection against GU models induced by absolute ethanol confirmed by biochemical and histological data.

Keywords: Gastric ulcer, Garlic, Omega 3, Gastroprotection.

(C) 2016 The Authors. Published by Innovare Academic Sciences Pvt Ltd. This is an open access article under the CC BY license (http://creativecommons. org/licenses/by/4. 0/) DOI: http://dx.doi.org/10.22159/ajpcr.2016.v9i5.12833

\section{INTRODUCTION}

Gastric ulcers (GU) and gastric lesions are serious diseases affecting a wide variety of individuals worldwide [1]. Imbalance between defensive mechanisms versus aggressive factors in the mucosa is the major etiology of GU and recently modulation of such imbalance may be the target of many researchers [2]. The risk of developing open sores in mucous lining of the stomach depends on several endogenous and exogenous factors including $\mathrm{HCl}$, pepsin, refluxed bile, Cytokines, free radicals, stress, nonsteroidal anti-inflammatory drugs, alcohol, and Helicobacter pylori [3]. Indeed cytokines such as tumor necrosis factor alpha, interleukin 6 (IL-6), and IL-10 play a key roles in the development and maintenance of gastric ulceration [4]. On the other hand, one of the common causes for the genesis of GU is the involvement of free radicals that play an important role in the pathogenesis of GU by lipid peroxidation and tissue lesions [5]. Normally, the gastric epithelium is exposed to high level of reactive oxygen species (ROS) derived from different microbiological, physical and chemical factors that normally eradicated by the action of endogenous antioxidant defense system [6]. Shifting of balance toward oxidative stress leads to apoptosis and necrosis of gastric epithelium. In general, there are a wide variety of antioxidative compounds play an essential role in ulcer treatment based on it is role in oxidative stress [7]. In this respect, garlic could be the most promising compound for the prevention and treatment of GU diseases for it is strong antioxidant action by powerful free radical scavenging capacity, enhancing cellular antioxidant enzymes activity like catalase, glutathione peroxidase, and superoxide dismutase. Add to garlic has some anti $H$. pylori activity [8]. Furthermore, there have been many literature, reports and researches indicating the pharmacological importance of garlic as anticancer, in cardiovascular disorders, neurological diseases, liver diseases, allergy and arthritis for their antioxidant and anti-inflammatory properties [9]. Another compound largely known for their antioxidant property was omega $3[10]$. The clinical importance of omega 3 (polyunsaturated fatty acid) in cardiovascular, cancers and inflammatory diseases, including arthritis, ulcerative colitis, and psoriasis are well documented [11]. It also exhibits promising effects in the treatment of fatty liver disease and has displayed protective roles against gastric lesions caused by several stimuli $[12,13]$.For our information, this is the first article studied the effect of pharmacological doses of omega 3 and garlic oils for treatment of GU in mice.

This study was designed to evaluate and compare the possible protective effect of pharmacological doses of garlic and omega 3 against gastric lesions induced by ethanol in mice.

\section{METHODS}

Chemicals

Garlic (500 mg softgel) and omega 3 (1000 mg softgel) were purchased from Vitane's Nature Pharmaceutical Company, USA. Ranitidine was purchased from SDI Company Samarra, Iraq. Diethyl ether was purchased from May and Baker, England while absolute obtained from BDH chemicals, Ltd., Poole, England, respectively.

\section{Animals}

A total of 30 albino mice (30-35 g) of both sexes were involved in the study. The mice were obtained from College of science, Basrah University and housed in the animal house of College of Pharmacy, Basrah University, Iraq. The mice were housed under a 12-hrs lightdark cycle and controlled condition (around $25^{\circ} \mathrm{C}$ ) and (air volume change 20 times/hrs) with two mice per cage. The mice were allowed to acclimatize for 7 days before the experiment and received standard diet and water ad libitum. Animal experiments were approved by the Animal Ethics Committee of Pharmacy College, Al-Basrah University.

\section{Experiment and mice treatment design}

The mice were divided into five groups consisting of 6 mice each: Groups 1 (ulcer control), Group 2 (normal control) received distilled water at a dose of $(3 \mathrm{ml} / \mathrm{kg})$, the other three groups are treated with one of the followings: Ranitidine ( $50 \mathrm{mg} / \mathrm{kg}$ ), garlic oil $200 \mathrm{mg} / \mathrm{kg}$, and omega 3 oil $150 \mathrm{mg} / \mathrm{kg}$. Pharmacological doses of garlic and omega 3 were precisely calculated based on the previous papers in which such 
compounds used as anti-inflammatory or antioxidants [14,15]. Al groups treated orally once daily for 14 days using gavage needle before GU induction. Subsequently in the $15^{\text {th }}$ day of treatment and after $24 \mathrm{hrs}$ fasting with free access to water, all mice received regular calculated doses of drugs and vehicle just $1 \mathrm{hr}$ before GU induction.

\section{Induction of GU}

In this GUs mice model, absolute ethanol was administered according to a method of Palacios-Espinosa et al. with slight modification [16]. $7 \mathrm{ml} / \mathrm{kg}$ absolute ethanol was administrated orally to all mice except in normal control group. Then $3 \mathrm{hrs}$ later, the animals in all groups were sacrificed by inhalation of a very high dose of diethyl ether. Subsequently, abdomen was opened and the stomach was excised and examined for the ulcers in stomach, it has been found that stomach of ulcer mouse was inflated may be due to oversecretion of gastric acidity as shown in Fig. 1.

\section{Evaluation of ulcer area and gastroprotection}

The stomach's ulcerative lesions were examined by the aid of digital pictures under a dissection microscope, measurement of ulcer area done using software UTHSCSA image tool 3.0 program for calculation ulcer area $[17,18]$. The summation of total ulcer areas $\left(\mathrm{mm}^{2}\right)$ divided by 6 (total mice number in each group) to achieve the mean ulcer area or what is called ulcer index (UI). Meanwhile, gastroprotection percent was measured using the equation [19]: \% Gastroprotection=([UA control-UA treated] $\times 100$ )/UA control.

\section{Evaluation of gastric mucus content}

The amount of gastric mucus was measured using a piece of glass slide were gently scraped the mucus for its evaluation. The mucus obtained was weighed using sensitive electronic weighing balance.

\section{Histopathological assessment}

At first, the collected gastric tissue samples fixed in $10 \%$ formalin solution for 4 days, sectioned, and then subsequently processed for routine paraffin blocking. Sections were cut at 4-5 $\mu \mathrm{m}$ and stained with hematoxylin and eosin [20], then observed under a dissection microscope by a special histopathologist for evaluation

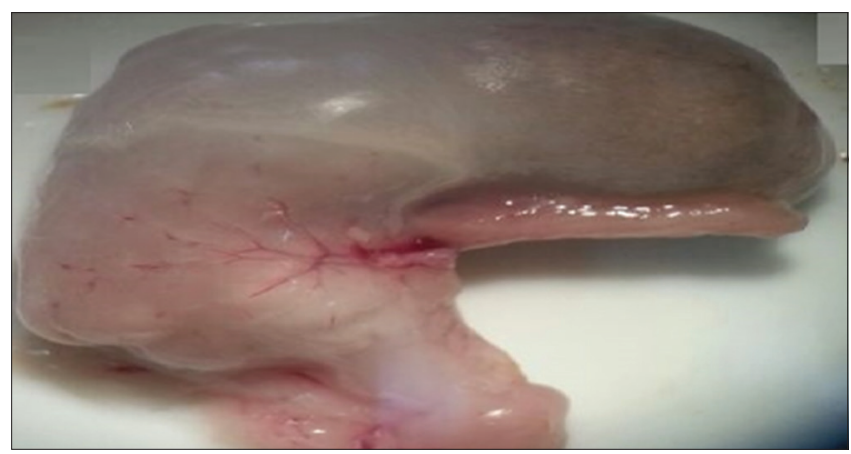

Fig. 1: Inflated stomach with acute ulcer due to absolute ethanol administration

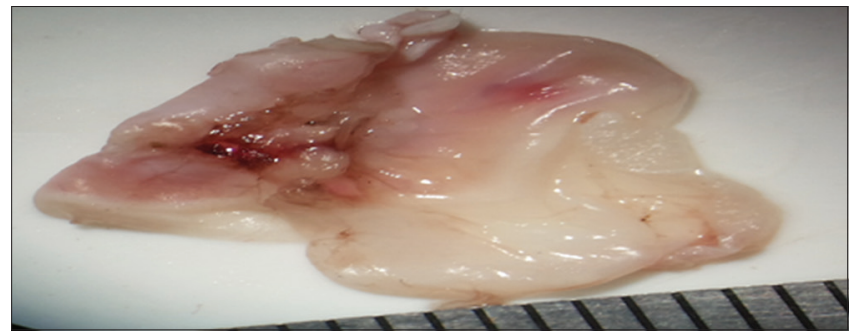

Fig. 2: Photograph under a dissection microscope of gastric mucosa in ulcer group, associated with hemorrhage and inflammation for histopathological change such as congestion, edema, erosions, ulcerations, and necrosis.

\section{Statistical analysis}

The results of this study expressed as mean \pm standard deviation; the data were analyzed using one-way analysis of variance. Values with $\mathrm{p}<0.05$ were considered significantly different. Analysis was performed using GraphPad Prism software version 5.0.

\section{RESULTS}

Macroscopic evaluation of stomach

The stomach's ulcerative areas were examined by a 10 magnifier lens under dissection microscope to assess ulcers areas. The numbers of ulcers were counted and scored. Ethanol lead to deep ulcer lesions characterized by inflammation combined with hemorrhage and edematous lesions observed in ulcer control group in contrast to normal control group no lesions were observed, as seen in Figs. 2 and 3.

\section{Effect of garlic and omega 3 on ethanol-induced gastric lesions}

The treatment with garlic and omega 3 ameliorated the severity of gastric ulceration. The positive control ranitidine significantly reduced the gastric lesions compared with treated groups as shown in Figs. 4-6.

\section{Histopathological investigation}

Histopathological investigation further confirmed the results that absolute ethanol-induced severe hemorrhage, edema, necrosis, and congestion in stomach mice sections. Such effect markedly ameliorated

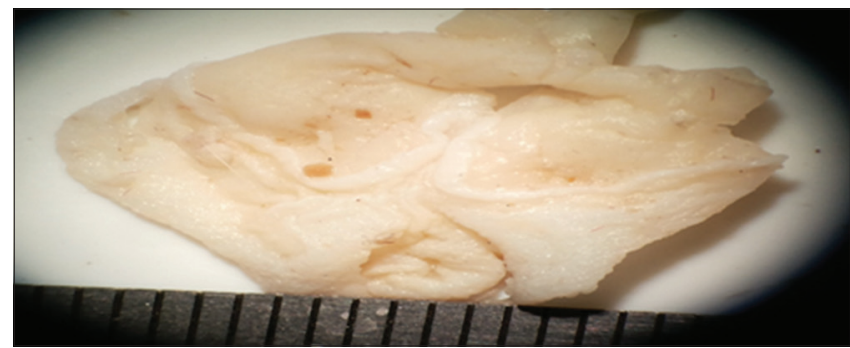

Fig. 3: Photograph of gastric mucosa in normal control group

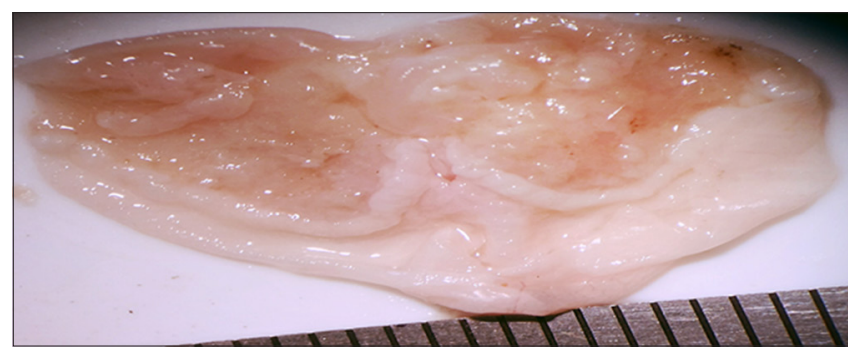

Fig. 4: Photograph of gastric mucosa under a dissection microscope in ranitidine treated group

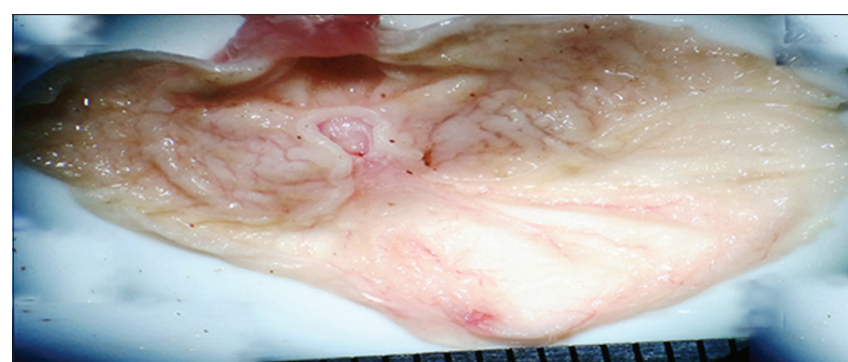

Fig. 5 Photograph of gastric mucosa under a dissection microscope in garlic treated group 
by ranitidine pretreatment, and to a lesser extent by omega 3 and garlic as shown in Fig. 7.

\section{UI and \% gastroprotection}

Oral administration of absolute ethanol-induced extensive gastric ulcerations in the gastric mucosa of the stomach (lesion area $=24.5 \pm 0.85$ ); actually, pretreatment with garlic and omega 3 reduced ethanol-induced mucosal damage significantly with a mean difference 16.3 reduction in omega 3 treated group and 16.61 in garlic treated group in the ulcer size compared with ulcer control group. Furthermore, the gastroprotective effect of garlic and omega 3 had been shown to be comparable with significantly different from that observed in positive control and ulcer control groups, highest gastroprotection percent observed in the positive control group as seen in Figs. 8 and 9.

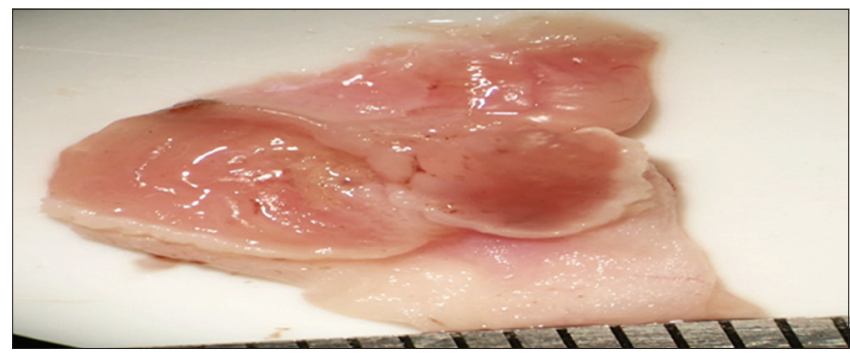

Fig. 6: Gastric mucosa photograph under dissection microscope in omega 3 treated group

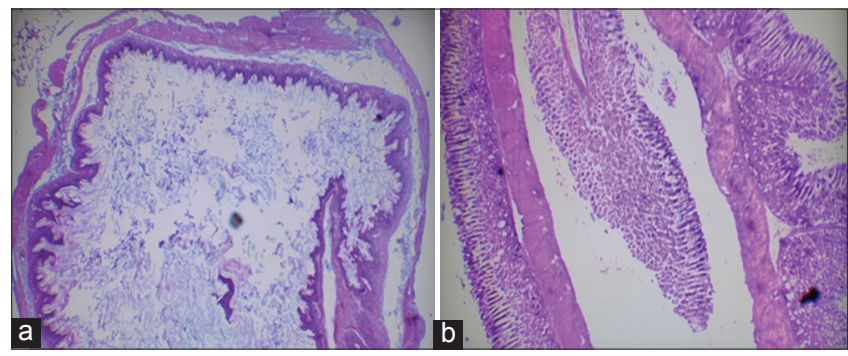

Fig. 7: Photomicrographs of gastric mucosa stained with hematoxylin and eosin $(\times 100)$. (a) Ulcer control; (b) normal control

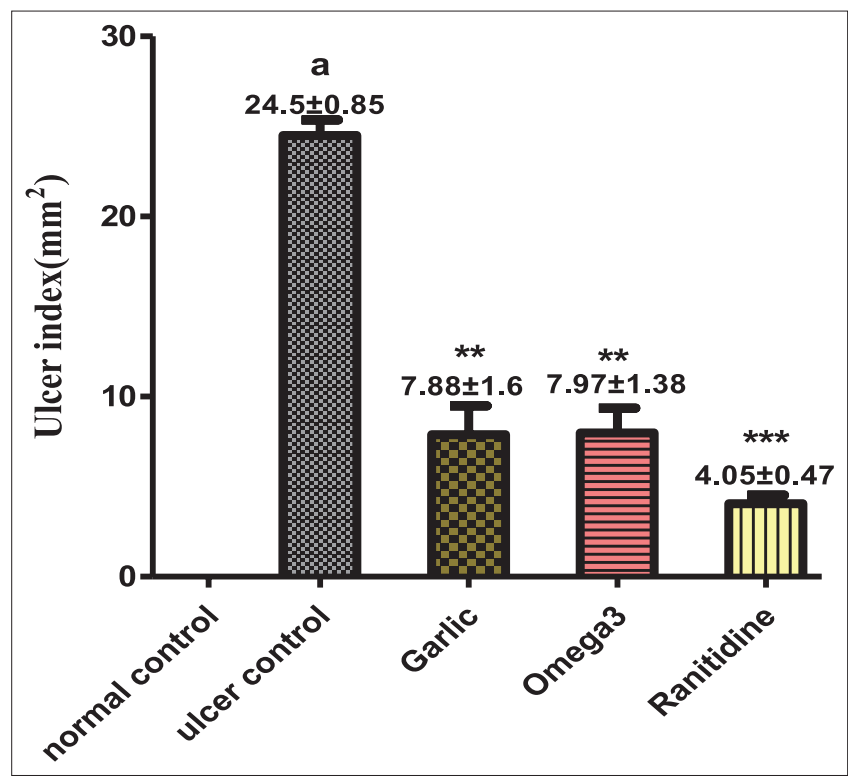

Fig. 8: Gastric ulcer index of gastric lesions induced by absolute ethanol in mice $(\mathrm{n}=6)$, analysis of variance: $* * \mathbf{p}<0.01, * * * \mathbf{p}<0.001$ compared to normal and ulcer control group, ${ }^{\text {a }} \mathbf{p}<0.001$ compared to normal control and all treated groups
Evaluation of gastric mucus content

There was a significant increase in viscosity of gastric mucus content in both garlic and omega 3 treated groups, tested compound antagonize mucus depletion by absolute ethanol but such effect less significant compared with ranitidine treated group (positive control as shown in Fig. 10 .

\section{DISCUSSION}

Ethanol-induced GU was widely used as an experimental model to determine the gastric healing effect of different compounds because it is closely resembles chronic ulcers in humans, particularly in the healing process. Furthermore such model is linked to the increase release of free radicals (mainly oxygen species), production of inflammatory mediators, stasis of blood flow and microvascular damage lead to hemorrhage and necrotic lesion [21,22]. In the stomach, $\mathrm{H}+$ ion secretion is an oxidant-dependent process and in the presence of

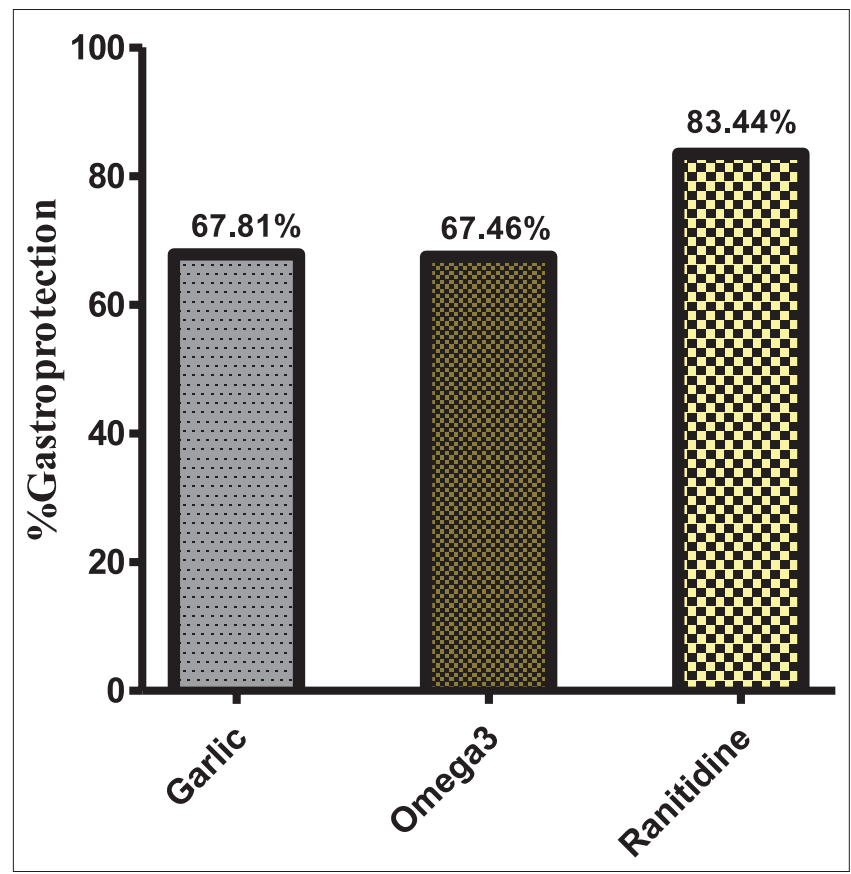

Fig. 9: Gastroprotection \% of both garlic and omega 3 oils against acute gastric lesions induced by absolute ethanol in mice $(n=6)$

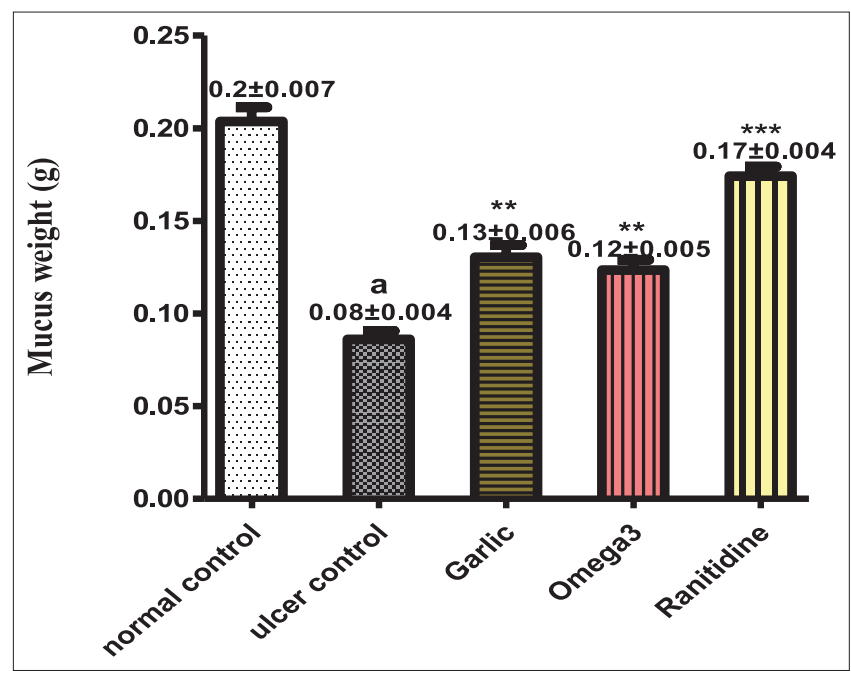

Fig. 10: Mucus content in the stomach of control and all treated groups in mice $(n=6)$, analysis of variance: ${ }^{* *} p<0.01, * * * p<0.001$ compared to normal and ulcer control group, ${ }^{\mathrm{a}} \mathrm{p}<0.001$ compared to normal control and all treated groups 
Cl- and $\mathrm{H}_{2} \mathrm{O}_{2}$, hydrochloric acid will be formed and these are very toxic oxidant that leads to mucosal lesion and lipid peroxidation, and this is the major pathogenesis of ulcer [23]. The endogenous anti-oxidant enzymes catalase, superoxide dismutase and glutathione in the gastric mucus are the key components of cellular defense system against stress induced ulcer and shifting the balance toward endogenous antioxidan is the target [24]. Furthermore, elevated ROS is a critical factor in the onset and development of various gastric disorders [25]. Hence, the general approach is to reduce ROS production that can provide a beneficial effect in combat gastric diseases. In this study, both garlic and omega 3 provide a promising gastroprotective effect on ethanolinduced GU explained by a significant reduction in ulcer area and significant increase in mucus content as compared with ulcer group. An important explanation of such results is scavenging capacity of the studied compounds lead to free radicals eradications [26]. Garlic is good traditional medicines have been widely used in prevention or management of GUs for a long time [27]. It seems that garlic protect gastric mucosa from absolute ethanol injury through neutralization of released free radicals and increase mucus content. This came in concurs with Borek (2001) who reported that garlic inhibits lipid peroxidation and reduces free radical induced transcription factor and nuclear factor kappa B, thus protecting mucosa from injury [28]. In addition, garlic contains antioxidant phytochemicals that prevent oxidants damage and protect gastric mucosa against oxidative stress [26]. In contrast for such finding, Oboh (2005) reported that garlic induced oxidative stress and produced hepatotoxicity [29]. The another compound used in this study was omega 3 or what is called fish oil is rich in polyunsaturated fatty acids like eicosapentaenoic acid and docosahexaenoic acid and such compounds considered gastroprotective after exposure to several insults [30]. Several studies [31,32] indicate the gastroprotective effect of fish oil against oxidative stress, this study demonstrates that administration of omega 3 in supraphysiological or pharmacological doses induced gastroprotection in an absolute ethanol-induced gastric injury in mice model. It has been found that omega 3 save and protect gastric mucosa against aspirin, cold restraint stress and alcohol by acting on both aggressive (decrease significantly acid-pepsin secretion) and defensive (mucin and gastric mucus secretion) gastric mucosal factors [31]. Another explanation of such result, omega 3 exert a range of anti-inflammatory effects including reduced inflammatory cytokine, adhesion molecule production, platelet activating factor, IL-6 also decreased leukocyte-adhesive interactions [33,34]. The comparable efficacy of garlic and omega 3 against gastric lesions in the present study found is consistent with the similarity of the mechanisms whereby that support their efficacy on this model as free radical scavenger [28,32] From this omega, 3 intake is associated with a decreased risk of different inflammatory diseases such as Crohn's disease, ulcerative colitis, rheumatoid arthritis, and asthma by modulation of inflammatory events [34].

\section{CONCLUSION}

Supraphysiologic or pharmacological oral doses of both garlic and omega 3 oils show significant gastroprotective effects against absolute ethanol-induced GU confirmed by cytoprotective, histological, antisecretory and biochemical data.

\section{REFERENCES}

1. Calam J, Baron JH. $\mathrm{ABC}$ of the upper gastrointestinal tract: Pathophysiology of duodenal and gastric ulcer and gastric cancer. BMJ 2001;323(7319):980-2.

2. Ateufack G, Nguelefack TB, Wabo HK, Watcho P, Tane P, Kamanyi A. Anti-ulcer effects of the aqueous and organic extracts of the stem bark of Anthocleista vogelii. in rats. Pharm Biol 2006;44:166-71.

3. Rang HP, Dale MM, Ritter M, Flower R. Pharmacology. $6^{\text {th }}$ ed Edinburgh: Churchill Living Stones; 2007. p. 385-90.

4. Choi JI, Raghavendran HR, Sung NY, Kim JH, Chun BS, Ahn DH, et al. Effect of fucoidan on aspirin-induced stomach ulceration in rats. Chem Biol Interact 2010;183(1):249-54

5. Mei XT, Xu DH, Xu SK, Zheng YP, Xu SB. Zinc(II)-curcumin accelerates the healing of acetic acid-induced chronic gastric ulcers in rats by decreasing oxidative stress and downregulation of matrix metalloproteinase-9. Food Chem Toxicol 2013;60:448-54.

6. Valko M, Leibfritz D, Moncol J, Cronin MT, Mazur M, Telser J. Free radicals and antioxidants in normal physiological functions and human disease. Int J Biochem Cell Biol 2007;39(1):44-84.

7. Jaccob AA. Protective effect of $\mathrm{N}$-acetylcysteine against ethanolinduced gastric ulcer: A pharmacological assessment in mice. J Intercult Ethnopharmacol 2015;4(2):90-5.

8. Cellini L, Di Campli E, Masulli M, Di Bartolomeo S, Allocati N. Inhibition of Helicobacter pylori by garlic extract (Allium sativum). FEMS Immunol Med Microbiol 1996;13(4):273-7.

9. Yun HM, Ban JO, Park KR, Lee CK, Jeong HS, Han SB, et al. Potential therapeutic effects of functionally active compounds isolated from garlic. Pharmacol Ther 2014;142(2):183-95.

10. Hajianfar H, Paknahad Z, Bahonar A. The effect of omega-3 supplements on antioxidant capacity in patients with type 2 diabetes. Int J Prev Med 2013;4 Suppl 2:S234-8.

11. Nordøy A. Is there a rational use for $n-3$ fatty acids (fish oils) in clinical medicine? Drugs 1991;42:331-42.

12. Masterton GS, Plevris JN, Hayes PC. Review article: Omega-3 fatty acids - A promising novel therapy for non-alcoholic fatty liver disease. Aliment Pharmacol Ther 2010;31(7):679-92.

13. Pineda-Peña EA, Jiménez-Andrade JM, Castañeda-Hernández G Chávez-Piña AE. Docosahexaenoic acid, an omega-3 polyunsaturated acid protects against indomethacin-induced gastric injury. Eur J Pharmacol 2012;697(1-3):139-43.

14. Mabrouk MA, Nnawodu FI, Tanko Y, Dawud F, Mohammed A. Effect of aqueous garlic (Ag) extract on aspirin induced gastric mucosal lesion in albino wistar rats. Curr Res J Biol Sci 2009;1(2):15-9.

15. Kokacya MH, Inanir S, Copoglu US, Dokuyucu R, Erbas O. The Antipsychotic effects of omega-3 fatty acids in rats. Am J Med Sci 2015;350(3):212-7.

16. Li WF, Hao DJ, Fan T, Huang HM, Yao H, Niu XF. Protective effect of chelerythrine against ethanol-induced gastric ulcer in mice. Chem Biol Interact 2014;208:18-27.

17. Sousa AT, Vasconcelos JM, Soares MJ. Software image tool 3.0 as an instrument for measuring wounds. J Nurs UFPE Online 2012;6(10):2569-73.

18. Palacios-Espinosa JF, Arroyo-García O, García-Valencia G, Linares E, Bye R, Romero I. Evidence of the anti-Helicobacter pylori, gastroprotective and anti-inflammatory activities of Cuphea aequipetala infusion. J Ethnopharmacol 2014;151:990-8.

19. Navarrete A, Trejo-Miranda JL, Reyes-Trejo L. Principles of root bark of Hippocratea excelsa (Hippocrataceae) with gastroprotective activity. J Ethnopharmacol 2002;79:383-8.

20. Laine L, Weinstein WM. Histology of alcoholic hemorrhagic "gastritis": A prospective evaluation. Gastroenterology 1988;94:1254-62.

21. Salga MS, Ali HM, Abdulla MA, Abdelwahab SI. Gastroprotective activity and mechanism of novel dichlorido-zinc(II)-4-(2-(5methoxybenzylideneamino)ethyl)piperazin-1-iumphenolate complex on ethanol-induced gastric ulceration. Chem Biol Interact 2012;195(2):144-53.

22. Rodrigues e Silva AA, Marques Bezerra M, Vasconcelos Chaves H, de Paulo Teixeira Pinto V, de Souza Franco E, Magalhães Vieira A, et al. Protective effect of Chresta martii extract on ethanol-induced gastropathy depends on alpha-2 adrenoceptors pathways but not on nitric oxide, prostaglandins or opioids. J Ethnopharmacol 2012;142(1):206-12.

23. Moncada S, Higgs A. The L-arginine-nitric oxide pathway. N Engl J Med 1993;329(27):2002-12

24. Nartey ET, Ofosuhene M, Agbale CM. Anti-ulcerogenic activity of the root bark extract of the African laburnum "Cassia sieberiana" and its effect on the anti-oxidant defence system in rats. BMC Complement Altern Med 2012;12:247.

25. Oliveira C, Kassab P, Lopasso FP, Souza HP, Janiszewski M, Laurindo FR, et al. Protective effect of ascorbic acid in experimental gastric cancer: Reduction of oxidative stress. World J Gastroenterol 2003;9(3):446-8.

26. Kalayarasan S, Sriram N, Sureshkumar A, Sudhandiran G. Chromium (VI)-induced oxidative stress and apoptosis is reduced by garlic and its derivative S-allylcysteine through the activation of $\mathrm{Nrf} 2$ in the hepatocytes of wistar rats. J Appl Toxicol 2008;28(7):908-19.

27. Choudhary M, Kumar V, Singh S. Gastric antisecretory and cytoprotective effects of hydroalcoholic extracts of Plumeria alba Linn. Leaves in rats. J Integr Med 2014;12(1):42-51.

28. Borek C. Antioxidant health effects of aged garlic extract. J Nutr 
2001:131(3s):1010S-5.

29. Oboh G. Hepatoprotective property of ethanolic and aqueous extracts of fluted pumpkin (Telfairia occidentalis) leaves against garlic-induced oxidative stress. J Med Food 2005;8(4):560-3.

30. Manjari V, Das UN. Effect of polyunsaturated fatty acids on dexamethasone-induced gastric mucosal damage. Prostaglandins Leukot Essent Fatty Acids 2000;62(2):85-96.

31. Bhattacharya A, Ghosal S, Bhattacharya SK. Effect of fish oil on offensive and defensive factors in gastric ulceration in rats.
Prostaglandins Leukot Essent Fatty Acids 2006;74(2):109-16.

32. Lugea A, Videla S, Vilaseca J, Guarner F. Antiulcerogenic and antiinflammatory actions of fatty acids on the gastrointestinal tract. Prostaglandins Leukot Essent Fatty Acids 1991;43:135-40.

33. Yates CM, Calder PC, Ed Rainger G. Pharmacology and therapeutics of omega-3 polyunsaturated fatty acids in chronic inflammatory disease. Pharmacol Ther 2014;141(3):272-82.

34. Simopoulos AP. Omega-3 fatty acids in inflammation and autoimmune diseases. J Am Coll Nutr 2002;21(6):495-505. 